\title{
Dissimilaridade genética e análise de trilha de cultivares de soja avaliada por meio de descritores quantitativos
}

\author{
João Paulo Gonsiorkiewicz Rigon*1, Silvia Capuani', José Félix de Brito Neto², Genésio Mário da Rosa , \\ Arci Dirceu Wastowski ${ }^{3}$, Carlos Alberto Gonsiorkiewicz Rigon ${ }^{4}$
}

\section{RESUMO}

Além das avaliações entre genótipos, a utilização de técnicas multivariadas possibilita restringirem-se os erros, principalmente quanto à diversidade genética, podendo-se, assim, prever combinações com maior efeito heterótico, além da maior possibilidade de recuperação dos genótipos superiores. Objetivou-se, com este trabalho, avaliar a divergência genética entre 18 cultivares de soja, por meio de seis caracteres morfoagronômicos. Foi realizada a análise de trilha, para averiguar as contribuições direta e indireta desses caracteres sobre o rendimento de grãos. A distância generalizada de Mahalanobis fundamentou as técnicas de agrupamentos, tanto a de Tocher, bem como a do dendrograma por ligação simples. Observaram-se cinco grupos divergentes, sendo nove genótipos considerados similares entre si, enquanto os cultivares CEP 59, Netuno e Urano foram formadores de grupos isolados pelos dois métodos de agrupamento. Quanto à análise de trilha, observou-se que os caracteres indiretos pouco influenciaram o rendimento de grãos, tendo relação direta significativa com massa de 100 grãos, tendo-se destacado os cultivares Tertulha e CEP 53, com produtividade de grãos acima de 3,7 t ha-1 .

Palavras-chave: agrupamento, Glycine $\max (\mathrm{L}$.$) Merr., divergência genética.$

\section{ABSTRACT}

\section{Genetic diversity and path analysis of soybeans cultivars evaluated by means of quantitative descriptors}

In addition to the evaluations among genotypes, the use of multivariate techniques enables to restrict errors, mainly concerning genetic diversity, and therefore to predict combinations with greater heterotic effect, and the greater possibility of recovery of superior genotypes. The objective of this study was to evaluate the genetic divergence between 18 soybean cultivars based on six morphological characteristics. Path analysis was performed to verify the contribution of direct and indirect characters on grain yield. The Mahalanobis distance has founded techniques of both Tocher Method and dendrogram by Single Linkage. Five different groups were formed: with nine genotypes considered similar among them; while the cultivars CEP 59, Netuno and Urano formed groups isolated by the two grouping methods. The path analysis showed that the indirect characters had little influence on grain yield, with significant direct relationship with mass of 100 grain, and cultivars Tertulha and CEP 53 standing out with grain yields above 3.7 t.ha-1.

Key words: group; Glycine max L. Merrill; genetic divergence.

\footnotetext{
Recebido para publicação em 08/09/2011 e aprovado em 17/02/2012

'Engenheiros-Agrônomos. Mestrandos do Programa de Pós-Graduação em Agricultura da Faculdade de Ciências Agronômicas, Universidade Estadual Paulista Júlio de Mesquita Filho (UNESP), Campus Botucatu, Fazenda Experimental Lageado, Caixa Postal 237, Rua José Barbosa de Barros, 1780, 18610-307, Botucatu, São Paulo, Brasil. jprigon@ fca.unesp.br; silviacapuani@fca.unesp.br (*autor para correspondência)

${ }^{2}$ Engenheiro-Agrônomo, Doutor. Embrapa Algodão, Centro Nacional de Pesquisa do Algodão. Rua Oswaldo Cruz, 1143, Caixa Postal 174, Bairro Centenário, 58428-095, Campina Grande, Paraíba, Brasil. felix@cnpa.embrapa.br

${ }^{3}$ Químico, Doutor. Departamento de Agronomia da Universidade Federal de Santa Maria. Campus de Frederico Westphalen UFSM/CESNORS. Linha 7 de Setembro, s/n, Br 386, Km 80, 98400-000, Frederico Westphalen, Rio Grande do Sul, Brasil. genesio@ct.ufsm.br; wastowski@smail.ufsm.br

${ }^{4}$ Graduando em Agronomia. Universidade Federal de Santa Maria, Campus de Frederico Westphalen UFSM/CESNORS, Linha 7 de Setembro, s/n, Br 386, Km 80, 98400-000, Frederico Westphalen, Rio Grande do Sul, Brasil. ca_rigon@hotmail.com
} 


\section{INTRODUÇÃO}

Em função dos altos rendimentos e da ampla adaptação nas diferentes latitudes brasileiras, aliados ao alto teor proteico e lipídico, a cultura da soja constitui-se como a mais importante oleaginosa do mundo. Considerandose a safra brasileira de 2009/2010, a cultura obteve crescimento produtivo de cerca $20 \%$, influenciado principalmente pelo aumento de área, de praticamente dois milhões de hectares, em relação à da safra anterior (Conab, 2011).

A utilização de tecnologias e de materiais genéticos de alto potencial produtivo condicionou o aumento nos rendimentos. Porém, torna-se necessária, para ostentar incrementos cada vez mais compensatórios, a obtenção de materiais adaptados às condições edafoclimáticas de cada região (Câmara et al., 1998). No melhoramento genético da soja, para obtenção de populações segregantes, necessita-se da escolha dos genitores a serem cruzados. Além disso, as hibridações artificiais em plantas autógamas geralmente envolvem cruzamentos entre biparentais, sendo as maiores limitações a variação genética estreita e a recombinação baixa, devidas ao processo posterior de autofecundação. Neste sentido, uma forma de possibilitar a obtenção de progênies superiores é reunir informações sobre a superioridade agronômica e a divergência genética, para possibilitar combinações entre genitores, identificando o conjunto gênico mais amplo e a viabilidade de cruzamentos, podendo-se, assim, relacionálas por técnicas multivariadas biométricas (Miranda, 1998; Cruz et al. 2004).

Apesar da preocupação atual sobre a perda da diversidade vegetal, em razão da substituição de variedades crioulas por cultivares com base genética estreita, a variabilidade genética consiste na manutenção produtiva em resposta às adversidades sobre estresses (Rinaldi et al., 2007). Neste sentido, caracteres agronômicos e morfológicos são submetidos à análise multivariada, permitindo identificar informações entre inúmeros caracteres, possibilitando restringir os erros quanto à escolha de progenitores mais divergentes nos programas de melhoramento (Cruz et al., 2004).

O conhecimento dos graus de associação entre caracteres possibilita identificar variáveis que possam ser utilizadas na seleção indireta sobre outra variável, como a produtividade, principalmente quando a herdabilidade do caráter principal é baixa (Iqbal et al. 2003; Costa et al., 2004). O desdobramento das correlações entre as variáveis, em efeitos diretos e indiretos, por meio da análise de trilha, mede, independentemente de outras variáveis, a influência direta de um caráter sobre outro, seguindo o diagnóstico da multicolinearidade entre as variáveis explicativas e as independentes (Cruz et al., 2004). Desta forma, os resultados permitem identificar critérios de seleção para a produtividade da soja, como averiguado por Bizeti et al. (2004), Costa et al. (2004), Arshad et al. (2006), Alcântara Neto et al. (2011) e Santos et al. (2011). Objetivou-se, com este trabalho, estudar as relações diretas e indiretas das variáveis com o rendimento, além de quantificar a variabilidade genética, por meio do agrupamento dos cultivares de soja e a contribuição relativa das variáveis para a dissimilaridade genética, podendo-se, assim, identificar as combinações superiores promissoras.

\section{MATERIAL E MÉTODOS}

O ensaio foi conduzido no município de Guarani das Missões, pertencente à Região das Missões do Rio Grande do Sul, com latitude $28^{\circ} 08^{\prime} 27^{\prime \prime}$ sul, longitude $54^{\circ} 33^{\prime}$ 29 " oeste e altitude de 270 metros. O experimento foi conduzido em blocos casualizados, com três repetições, em solo predominantemente do tipo Latossolo Vermelho distrófico (Embrapa, 2006), sendo os tratamentos constituídos pelos 18 cultivares de soja: CD 214; CD 225; CD 226; CEP 59; CEP 55; CEP 53; SYN 9070; SYN 3358; SYN 9074; NK 7059; Dom Mário; Potência; Força; Impacto; Urano; Netuno; Titan; e Tertulha. As sementes foram submetidas à inoculação com estirpes de Bradyrhizobium japonicum, e secadas à sombra. Posteriormente, foi procedida a semeadura em sistema de plantio direto, no mês de dezembro de 2009, tendo como antecessora a cultura do trigo. O dimensionamento das parcelas foi de 4,95 x 5 $\mathrm{m}$, comportando 12 linhas de cultivo, espaçadas a $0,45 \mathrm{~m}$, com área útil 10,8 m².

A adubação utilizada foi baseada em resultados da análise de solo: Arg: 45\%; pH: 5,7; Índice SMP: 6,0; Pe K: 4,3 e 103 mg.L-1' MO: 32 g.Kg-1' ${ }^{1}$ Al: 0,2 cmolc.L-1' Ca 9,8 cmolc.L-1; Mg: 3,2 cmolc.L-1' CTC: 16,5 cmolc.L-1' H+AL: 3,1; Sat. Bases: 80,9 g.Kg-1 ${ }^{1}$, frente às exigência da cultura na expectativa para rendimentos de $3 \mathrm{t} \mathrm{ha}^{-1}$ (SBCS, 2004), sendo utilizados $250 \mathrm{Kg}$.ha- ${ }^{1}$ da fórmula 0-20-20.

Quanto aos tratamentos fitossanitários, foram utilizadas duas aplicações de fungicidas, de i.a. tebuconazole, em $150 \mathrm{~g}$ ha- ${ }^{1}$ do i.a., sendo a primeira aplicação em V7 e a segunda em R3. Para o controle de pragas, utilizou-se o inseticida de i.a. acefato, em dosagem de $750 \mathrm{~g}$ ha- ${ }^{1}$ do i.a.

Os caracteres mensurados foram: altura da inserção do primeiro legume (AIL) - distância, em cm, a partir da superfície do solo ao primeiro legume, obtida na época de maturação, em 10 plantas da área útil da parcela; altura das plantas (AP) - distância, em cm, a partir da superfície do solo até a extremidade da haste principal da planta, obtida na época da maturação, em 10 plantas da área útil; massa de 100 sementes (M100) - massa de 100 grãos com oito repetições, extrapolando-se para massa de 100 sementes; produtividade de grãos (PROD) - obtida por meio da trilha das plantas na área útil da parcela, descontada 
para umidade de $13 \%$. Maturação (MAT) - número de dias necessários para maturação físiológica de $50 \%$ das plantas em estádio R7.3; índice de acamamento (IA) contabilizado em estádio de maturação fisiológica, índice de 1 a 5 , sendo 1 pouco susceptível ao acamamento ao 5, completamente acamado.

Para a análise da dissimilaridade entre os cultivares, os valores foram ordenados conforme procedimento de Scott-Knott (Scott \& Knott, 1974), no qual a razão de verossimilhança atesta a significância entre a divisão dos grupos de tratamentos. Posteriormente, foi obtida a matriz de dispersão, empregando-se métodos multivariados, com base no método de agrupamento de ligação simples ou vizinho mais próximo, obtendo-se o dendrograma, utilizando-se a distância generalizada de Mahalanobis como medida de dissimilaridade. Foi aplicado, também, o critério de Singh (1981), para quantificar a contribuição das características para a divergência genética entre os cultivares (Cruz et al., 2004). Para a análise dos efeitos diretos e indiretos sobre o rendimento de grãos, foram realizadas as análises de trilha entre as variáveis, utilizando o programa Computacional Genes, versão 2008 (Cruz, 2008).

\section{RESULTADOS E DISCUSSÃO}

São apresentados, na Tabela 1, os efeitos diretos e indiretos das variáveis explicativas primárias sobre o rendimento de grãos na cultura da soja de 18 cultivares. $\mathrm{O}$ coeficiente de determinação revela que $64 \%$ do rendimento é explicado pelo efeito das variáveis analisadas. É importante salientar que a produtividade é um caráter quan-

Tabela 1. Estimativa dos efeitos diretos e indiretos dos caracteres maturação fisiológica (MAT), índice de acamamento (IA), altura de planta (AP), altura de inserção do primeiro legume (AIL) e massa de 100 grãos (M100) sobre o rendimento (REND) de cultivares de soja

\begin{tabular}{|c|c|c|c|c|}
\hline \multirow{2}{*}{ Caráter } & \multirow{2}{*}{ Vias de Associação } & \multicolumn{2}{|c|}{ Coeficientes de Trilha } & \multirow{2}{*}{$\begin{array}{l}\text { Coeficiente } \\
\text { de Correlação }\end{array}$} \\
\hline & & Efeito direto & Efeito indireto & \\
\hline \multirow{6}{*}{ MAT } & Efeito direto sobre REND & $-0,1728$ & & \\
\hline & Efeito indireto via IA & & $-0,0305$ & \\
\hline & Efeito indireto via AP & & 0,0215 & \\
\hline & Efeito indireto via AIL & & $-0,0602$ & \\
\hline & Efeito indireto via M100 & & 0,0398 & \\
\hline & Total & & & $-0,2022$ \\
\hline \multirow{6}{*}{ IA } & Efeito direto sobre REND & $-0,0891$ & & \\
\hline & Efeito indireto via MAT & & $-0,0592$ & \\
\hline & Efeito indireto via AP & & $-0,0901$ & \\
\hline & Efeito indireto via AIL & & $-0,0639$ & \\
\hline & Efeito indireto via M100 & & 0,2251 & \\
\hline & Total & & & $-0,08$ \\
\hline \multirow{6}{*}{ AP } & Efeito direto sobre REND & $-0,1896$ & & \\
\hline & Efeito indireto via MAT & & 0,0196 & \\
\hline & Efeito indireto via IA & & $-0,0423$ & \\
\hline & Efeito indireto via AIL & & $-0,0925$ & \\
\hline & Efeito indireto via M100 & & 0,1106 & \\
\hline & Total & & & $-0,1943$ \\
\hline \multirow{6}{*}{ AIL } & Efeito direto sobre REND & $-0,1477$ & & \\
\hline & Efeito indireto via MAT & & $-0,0704$ & \\
\hline & Efeito indireto via IA & & $-0,0386$ & \\
\hline & Efeito indireto via AP & & $-0,1189$ & \\
\hline & Efeito indireto via M100 & & $-0,0612$ & \\
\hline & Total & & & $-0,4369$ \\
\hline \multirow{6}{*}{ M100 } & Efeito direto sobre REND & 0,4673 & & \\
\hline & Efeito indireto via MAT & & 0,0147 & \\
\hline & Efeito indireto via IA & & 0,0424 & \\
\hline & Efeito indireto via $\mathrm{AP}$ & & 0,04491 & \\
\hline & Efeito indireto via AIL & & $-0,0193$ & \\
\hline & Total & & & 0,5432 \\
\hline \multicolumn{2}{|c|}{ Coeficiente de determinação } & & & 0,64 \\
\hline \multicolumn{2}{|c|}{ Efeito da variável residual } & & & 0,53 \\
\hline
\end{tabular}


titativo e com grandes alelos modificadores (pequeno efeito), sendo influenciados fortemente pelas condições do ambiente, e, consequentemente, de herdabilidade baixa. Deste modo, observa-se um sistema de inter-relações sobre o rendimento, com influência de outro caráter, denominado efeito indireto. Em função de os valores dos efeitos diretos sobre o rendimento serem inferiores aos obtidos via correlações, pode-se salientar que existem outras características exercendo influência nas correlações com a componente principal.

Observou-se relação direta positiva apenas para massa de 100 grãos com o rendimento, com coeficiente de correlação 0,54 , resultados semelhantes aos obtidos por Arshad et al. (2006), Iqbal et al. (2008), Almeida et al. (2010) e Malik et al. (2011) em estudos com a cultura da soja. Entretanto, os efeitos indiretos dos demais caracteres, pouco contribuíram com o componente principal. Isto indica a viabilidade da seleção indireta para obtenção de ganhos no caráter de maior importância primária, apesar de a melhor estratégia consistir na seleção de variáveis com efeitos indiretos significativos (Cruz et al. 2004).

No entanto, houve alta correlação negativa entre altura de inserção do primeiro legume com o rendimento. De acordo com Lopes et al. (2002), existe uma tendência em se valorizar mais o sinal, do que propriamente a magnitude dos valores das correlações entre os melhoristas, valorizando-se as estimativas abaixo de -0,5 e acima de 0,5.
Neste caso, aliam-se as correlações da maturação e altura de planta com a inserção do primeiro legume sobre o rendimento. Sendo assim, observou-se que o ciclo mais curto influi no incremento produtivo, possivelmente por menor exposição a fatores bióticos e abióticos, como reportado por Vieira (2007).

Da mesma forma, as menores alturas, pelo efeito indireto da inserção do primeiro legume, inferem sobre o rendimento de grãos, concordando com dados de Carvalho et al. (2002), em estudo com soja. Usualmente na cultura, a utilização de cultivares com menor altura de inserção do primeiro legume e maior altura de planta conduz ao ideótipo ideal, por possuir maior capacidade de massa de grãos por planta, conforme Miranda (1998). Além disso, a altura mínima da primeira vagem deve situar-se entre 10 e $15 \mathrm{~cm}$ para não possibilitar perdas na colheita na cultura da soja (Sediyama et al., 2005).

Analisando-se os efeitos indiretos entre os componentes, constataram-se magnitudes de interferência moderada; porém, algumas contribuições foram mais explicativas, como a AP e IA com efeitos medianos sobre M100 (0,11 e 0,22, respectivamente). Diferentemente, o efeito indireto proporcionado por AIL sobre AP foi negativo $(-0,11)$.

As médias das variáveis para cada cultivar são mostradas na Tabela 2. Observou-se que os caracteres altura de inserção do primeiro legume, altura de planta e índice

Tabela 2. Médias das variáveis para os 18 cultivares de soja, conforme procedimento de Scott-Knott

\begin{tabular}{|c|c|c|c|c|c|c|c|c|c|}
\hline Cultivares & AIL & $\mathbf{A P}$ & & M100 & REN & & MA & & IA \\
\hline CD 214 & $17,2 \mathrm{~b}^{*}$ & 105,0 & $\mathrm{a}$ & $13,29 \mathrm{~b}$ & 2730 & $\mathrm{c}$ & 140 & $\mathrm{a}$ & $1,8 \mathrm{a}$ \\
\hline CD 225 & $16,7 \mathrm{~b}$ & 122,5 & $\mathrm{a}$ & 14,64 a & 2610 & c & 127 & $\mathrm{~b}$ & $1,5 \mathrm{~b}$ \\
\hline CD 226 & $18,7 \quad b$ & 103,5 & $\mathrm{a}$ & 16,40 a & 3076 & $\mathrm{~b}$ & 130 & $\mathrm{a}$ & $1,4 \mathrm{~b}$ \\
\hline CEP 59 & 29,0 a & 107,2 & $\mathrm{a}$ & $16,84 \mathrm{a}$ & 2628 & $\mathrm{c}$ & 142 & $\mathrm{a}$ & $1,3 \mathrm{~b}$ \\
\hline CEP 55 & $8,8 \quad \mathrm{c}$ & 84,0 & $\mathrm{c}$ & $16,37 \mathrm{a}$ & 3276 & $\mathrm{~b}$ & 132 & $\mathrm{a}$ & $1,0 \mathrm{c}$ \\
\hline CEP 53 & $11,7 \mathrm{c}$ & 77,7 & $\mathrm{c}$ & $17,30 \mathrm{a}$ & 3720 & $\mathrm{a}$ & 134 & $\mathrm{a}$ & $1,1 \mathrm{c}$ \\
\hline SYN 3358 & $14,8 \quad \mathrm{c}$ & 90,2 & $\mathrm{~b}$ & $15,53 \mathrm{a}$ & 3060 & $\mathrm{~b}$ & 125 & $\mathrm{~b}$ & $1,1 \mathrm{c}$ \\
\hline SYN 9074 & $22,6 \quad b$ & 108,7 & $\mathrm{a}$ & 16,75 a & 3198 & $\mathrm{~b}$ & 135 & $\mathrm{a}$ & $1,8 \mathrm{a}$ \\
\hline NK 7059 & $11,5 \mathrm{c}$ & 98,4 & $\mathrm{~b}$ & 16,22 a & 3002 & $\mathrm{~b}$ & 128 & $\mathrm{~b}$ & $1,0 \mathrm{c}$ \\
\hline DOM MÁRIO & $19,7 \quad b$ & 108,5 & a & $13,64 \mathrm{~b}$ & 3000 & $\mathrm{~b}$ & 133 & $\mathrm{a}$ & $1,7 \mathrm{a}$ \\
\hline POTENCIA & $15,0 \quad \mathrm{c}$ & 94,1 & $\mathrm{~b}$ & 14,47 a & 3276 & $\mathrm{~b}$ & 135 & $\mathrm{a}$ & $1,2 \mathrm{~b}$ \\
\hline FORÇA & $22,0 \quad b$ & 107,8 & $\mathrm{a}$ & $13,40 \mathrm{~b}$ & 3210 & $\mathrm{~b}$ & 134 & $\mathrm{a}$ & $1,5 \mathrm{~b}$ \\
\hline IMPACTO & $21,6 \mathrm{~b}$ & 113,0 & $\mathrm{a}$ & 17,32 a & 3102 & $\mathrm{~b}$ & 133 & $\mathrm{a}$ & $1,7 \mathrm{a}$ \\
\hline URANO & $19,8 \mathrm{~b}$ & 75,1 & $\mathrm{c}$ & 22,41 a & 2010 & $\mathrm{c}$ & 134 & $\mathrm{a}$ & $1,0 \mathrm{c}$ \\
\hline NETUNO & $10,6 \mathrm{c}$ & 59,7 & $\mathrm{c}$ & $13,17 \mathrm{~b}$ & 3384 & $\mathrm{~b}$ & 139 & $\mathrm{a}$ & $1,5 \mathrm{~b}$ \\
\hline TITAN & $11,7 \mathrm{c}$ & 81,3 & c & 17,32 a & 2976 & $\mathrm{~b}$ & 134 & $\mathrm{a}$ & $1,0 \mathrm{c}$ \\
\hline TERTULHA & $11,8 \mathrm{c}$ & 91,3 & $\mathrm{~b}$ & $16,27 \mathrm{a}$ & 3780 & $\mathrm{a}$ & 125 & $\mathrm{~b}$ & $1,0 \mathrm{c}$ \\
\hline SYN 9070 & $22,6 \quad b$ & 107,2 & $\mathrm{a}$ & 15,33 a & 3176 & $\mathrm{~b}$ & 135 & $\mathrm{a}$ & $1,0 \mathrm{c}$ \\
\hline Média Geral & 16,61 & 97,38 & & 15,83 & 3080 & & 133 & & 1,34 \\
\hline $\begin{array}{l}\text { Coeficiente } \\
\text { de Variação (\%) }\end{array}$ & 13,85 & 8,65 & & 16,43 & 14 , & & 4 & 73 & 12,54 \\
\hline
\end{tabular}

*Médias seguidas pela mesma letra na coluna não diferem a 5\% de probabilidade, pelo procedimento de Scott-Knott. AIL: Altura de inserção do $1^{\circ}$ legume; AL: altura de planta (cm); M100: massa de 100 grãos (g); REND: Rendimento (Kg.ha-1); MAT: Maturação (dias); IA: Índice de acamamento

Rev. Ceres, Viçosa, v. 59, n.2, p. 233-240, mar/abr, 2012 


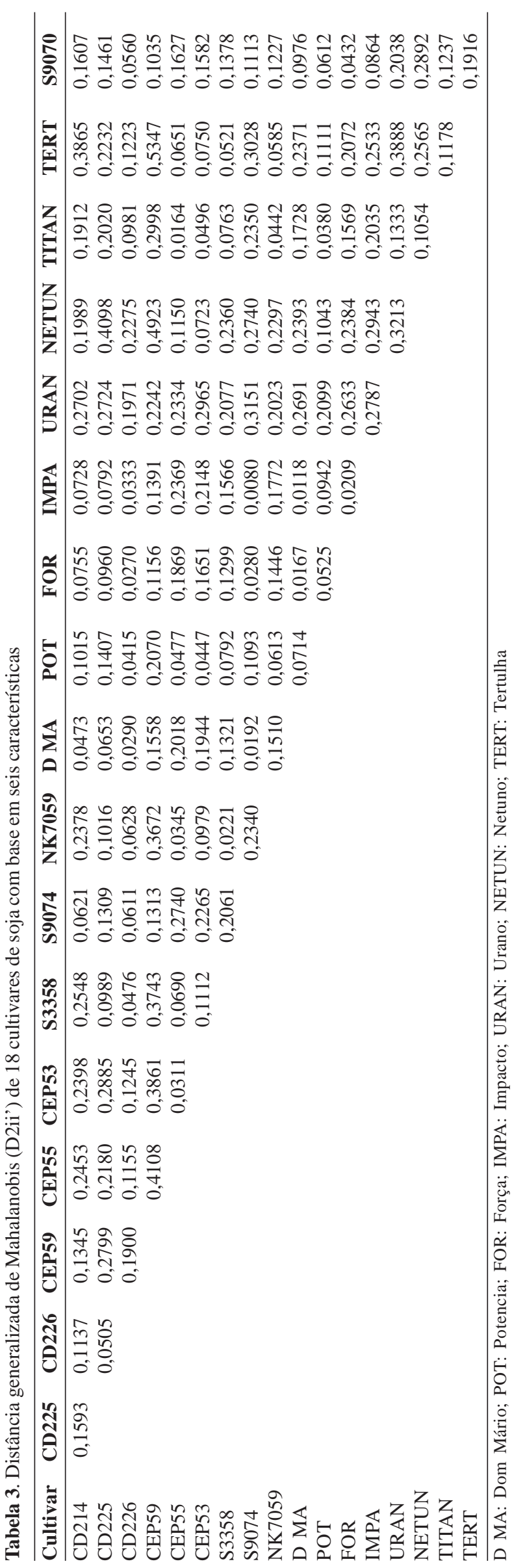

de acamamento posicionaram-se em classes semelhantes, evidenciando certa relação entre estas variáveis, como constatado na análise de trilha. Em relação ao rendimento de grãos, a média obtida foi de $3 \mathrm{t} \mathrm{ha-}^{-1}$, próxima à dos dados obtidos por Behling et al. (2009) em Seropédica RJ, em estudo com 10 cultivares de soja, assim como os de Almeida et al. (2011) e de Santos et al. (2011), em estudo com 12 e 48 cultivares de soja, respectivamente, em Formoso do Araguaia - TO. A média produtiva equiparouse também à expectativa nacional para a safra 2011/2012, de 2,9 t ha- $^{-1}$ (Conab, 2011). Dentre os cultivares mais produtivos destacaram-se o Tertulha, registrado a partir da última safra à comercialização, e o Cep 53.

No tocante à divergência genética, as medidas de dissimilaridade foram estimadas a partir da distância de Mahalanobis (Tabela 3). Observou-se elevada magnitude nas distâncias, desde $\mathrm{D}^{2}$ : 0,008 à 0,53 , indicando presença de alta variabilidade genética. Vieira et al. (2009) averiguaram a distância genética em 53 cultivares de soja, entre 0,02 e 0,73 , separadas em sete grupos, assim como Brown-Guerida et al. (2000), em experimento com 105 acessos de soja, com distanciamento variando entre $0,08 \mathrm{e}$ 0,76 , formando 11 grupos distintos. Desta forma, houve grande divergência entre os cultivares estudados, assim como ampla variabilidade, segundo constataram outros trabalhos entre genótipos de soja, como os de Sihag et al. (2004), Chettri et al. (2005) e Malik et al. (2007).

Quanto menor a distância, têm-se indivíduos genéti$\cos$ semelhantes ou parentais. Isto foi averiguado entre os cultivares Impacto e Syn $9074\left(D^{2}=0,008\right)$, assim como entre o cultivar Impacto e o Dom Mário $\left(D^{2}=0,01\right)$; Dom Mário e Força $\left(D^{2}=0,016\right)$ e CEP 55 e Titan $\left(D^{2}=0,016\right)$, enquanto as combinações mais divergentes apareceram entre Tertulha e CEP $59\left(D^{2}=0,53\right)$; Netuno e CD 225 e CEP $59\left(D^{2}=0,40\right.$ e 0,39$)$, CEP 53 e CEP 59 , com distanciamento de 0,38 .

A distância generalizada de Mahalanobis permitiu quantificar a importância relativa de caracteres para a diversidade genética, por meio da avaliação da contribuição dos caracteres para os valores de $\mathrm{D}^{2}$. Assim como verificado por Azevedo et al. (2004), Almeida et al. (2011) e Santos et al. (2011) na cultura da soja. Neste sentido, a aplicação do método de otimização de Tocher, baseada na matriz de Mahalanobis, separou os indivíduos em cinco grupos (Tabela 4), sendo metade dos genótipos reunidos no grupo I (SYN 9074, Impacto, Dom Mário, Força, CD 226, Potencia, Syn 9070, CD 214 e CD 225) e seis cultivares no grupo II (CEP 55, Titan, NK 7059, Syn 3358, CEP 53 e Tertulha). Entretanto, os grupos III, IV e V foram mais intensamente divergentes e assim, constituídos por apenas um genótipo em cada nível, composto pelos cultivares Netuno, Urano e CEP 59, respectivamente. Observouse que os resultados obtidos pelo agrupamento de Tocher 
confirmaram os distanciamentos expressos na Tabela 4, tanto para os indivíduos mais similares, quanto para os mais divergentes. A formação desses grupos representa valiosa informação dentro do programa de melhoramento, pois a de cultivares em grupos mais distantes fornece o indicativo de serem dissimilares, podendo ser considerados mais aptos aos cruzamentos artificiais (Abreu et al., 1999).

O método utilizado de aglomerativo Ligação Simples por vizinho mais próximo tem a finalidade de reunir indivíduos mais similares entre si; em seguida, identificar o novo par mais semelhante para formar outro par de indivíduos e, assim, sucessivamente, formando grupos de acordo com suas similaridades (Cruz et al. 2004). Este procedimento também foi realizado em outros estudos sobre divergência na cultura da soja (Peluzio et al. 2009; Almeida et al., 2011).

O dendrograma (Figura 1) representa bem os agrupamentos dos cultivares de soja. Verifica-se que os cultivares Syn 9074, Impacto, Dom Mário, Força e CD 226 tiveram encadeamento próximo, representando a mesma conformação do grupo I pelo método de Tocher (Tabela 4). Da mesma forma, Syn 3358, HK 7059, CEP 55, Titan e CEP 53 formaram nova sequência de similaridade no dendrograma, tendo a mesma representação do grupo II. Potencia, Syn 9070, CD 214 e CD 225 formaram novo encadeamento de ligação entre grupos, embora presentes no grupo I (Tabela 4), possivelmente por serem similares, mas com médias maiores que as do encadeamento anterior. Os demais cultivares, Netuno, Cep 59 e Urano foram os mais divergentes, assim como verificado pelo método de Tocher. Portanto, os agrupamentos do dendrograma mostraram-se semelhantes aos obtidos pelo método de Tocher, concordando com os de Santos et al. (2011), em estudo da divergência em soja. Além disso, foi observado coeficiente de correlação cofenético de magnitude 0,75 , sendo considerado de boa estimativa.

Dentre as variações entre os caracteres avaliados, o parâmetro de maior influência, e, consequentemente, de mais intensa contribuição para a divergência genética, foi a altura de inserção do primeiro legume, seguido pela época de maturação fisiológica da soja, os quais contribuíram

Tabela 5. Contribuição relativa das variáveis em 18 cultivares de soja, conforme critério de Singh (1981)

\begin{tabular}{lcc}
\hline Variáveis & S.j. & Valor $(\%)$ \\
\hline Altura de inserção & 5,6760 & 23,0203 \\
do primeiro legume & 4,6361 & 18,8028 \\
Altura de planta & 0,8068 & 3,2723 \\
Massa de 100 grãos & 4,1118 & 16,6764 \\
Rendimento & 5,0021 & 20,2875 \\
Maturação fisiológica & 4,4235 & 17,9406 \\
Índice de acamamento &
\end{tabular}

Sj: contribuição da variável x para o valor da distância de Mahalanobis entre os cultivares

Tabela 4. Agrupamento de otimização entre dezoito cultivares de soja, obtido pelo método de Tocher, com base em seis características, utilizando a distância generalizada de Mahalanobis

\begin{tabular}{|c|c|c|c|c|c|c|c|c|}
\hline Grupo & & & & Indi & íduos & & & \\
\hline $\mathrm{I}$ & SYN 9074 & IMPACTO & DOM MÁRIO & FORÇA & POTENCIA & SYN 9070 & CD 214 & CD 225 \\
\hline II & CEP 55 & TITAN & NK 7059 & SYN 3358 & CEP 53 TERTULHA & & & \\
\hline III & NETUNO & & & & & & & \\
\hline IV & URANO & & & & & & & \\
\hline V & CEP 59 & & & & & & & \\
\hline
\end{tabular}

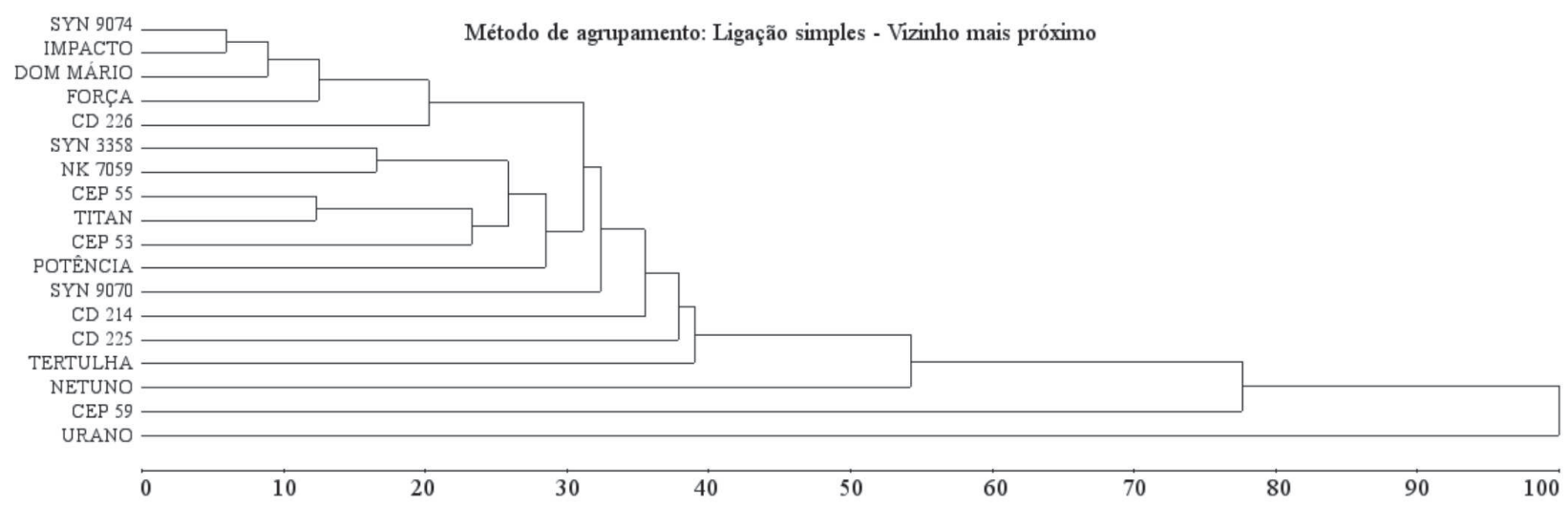

Figura 1. Dendrograma representativo da dissimilaridade genética entre 18 cultivares de soja, obtido pelo método de agrupamento ligação simples - vizinho mais próximo, utilizando a matriz generalizada de Mahalanobis. 
com 23 e $20 \%$, respectivamente (Tabela 5), enquanto a variável massa de 100 grãos pouco se distinguiu entre os indivíduos, com importântica de 3,27\%, similar aos dados reportados por Peluzio et al. (2009), com contribuição de $2,8 \%$. Esta pequena distinção entre os materiais deve-se, possivelmente, ao fato de o melhoramento genético deste caráter na cultura da soja ter sido intensificado, pois relaciona-se diretamente com o rendimento de grãos.

\section{CONCLUSÕES}

A distância generalizada de Mahalanobis fundamentou as técnicas de agrupamentos, tanto de Tocher, quanto do dendrograma por ligação simples com identificação de genótipos dissimilares com potenciais cruzamentos artificiais.

As variáveis de maior contribuição para a divergência foram a altura de inserção do primeiro legume e a época de maturação fisiológica.

Os caracteres indiretos pouco influenciaram o rendimento de grãos, tendo relação direta significativa com massa de 100 grãos, tendo-se destacado os cultivares Tertulha e CEP 53, com produtividades de grãos acima de 3,7 tha- ${ }^{1}$.

\section{REFERÊNCIAS}

Abreu A de FB, Ramalho MAP \& Ferreira DF (1999) Selection potential for seed yield from intra and inter-racial populations in common bean. Euphytica, 108:121-127.

Alcântara Neto F, Gravina G de A, Monteiro MM de S, Orais FB de, Petter FA \& Albuquerque JAA de (2011) Análise de trilha do rendimento de grãos de soja na microrregião do Alto Médio Gurguéia. Comunicata Scientiae, 2:107-112.

Almeida RD de, Peluzio JM \& Afferri FS (2010) Correlações fenotípicas, genotípicas e ambientais em soja cultivada sob condições de várzea irrigada, Sul de Tocantins. Bioscience Journal, 26:95-99.

Almeida RDA, Peluzio JM \& Afférri FS (2011) Divergência genética entre cultivares de soja, sob condições de várzea irrigada, no sul do Estado Tocantins. Revista Ciência Agronômica, 42:108-115.

Arshad M, Ali N \& Ghafoor A (2006) Character correlation and path coefficient in Soybean (Gycine max Merrill). Pakistan Journal of Botany, 38:121-130.

Azevedo PH, Azevedo VH, Sediyama T, Reis MS, Teixeira RC \& Cecon PR (2004) Divergência genética entre genótipos de soja ausentes de enzimas lipoxigenases. Revista Ceres, 51:663-670.

Behling M, Zonta E, Lima E \& Amaral Sobrinho NMB do (2009) Produtividade e desempenho vegetativo de dez cultivares de soja na Baixada Fluminense, Seropédica-RJ. Revista Ceres, 56:69-73.

Bizeti HS, Carvalho CGP de, Souza JRP de \& Destro D (2004) Path analysis under multicollinearity in soybean. Brazilian Archives of Biology and Technology, 47:669-676.

Brown-Guerida GL, Thompson JA, Nelson RL \& Warburton ML (2000) Evaluation of genetic diversity of soybean introductions and North American ancestors using RAPD and SSR markers. Crop Science, 40:815-823.
Câmara GMS, Piedade SMS, Monteiro JH \& Guerzoni RA (1998) Desempenho vegetativo e produtivo de cultivares e linhagens de soja de ciclo precoce no município de Piracicaba - SP. Scientia Agrícola, 55:395-408.

Carvalho FIF, Silva SA, Kurek AJ \& Marchiori VS (2002) Estimativas e implicações da herdabilidade como estratégia de seleção. Pelotas, Editora e gráfica da UFPel. 99p.

Chettri M, Mondal S \& Nath R (2005) Studies on genetic variability in Soybean (Glycine max (L.) Merril) in the mid hills of Darjeeling District. Journal of Interacademicia, 9:175-178.

Conab - Companhia Nacional de Abastecimento (2011) Acompanhamento de safra brasileira: grãos, terceiro levantamento, dezembro 2011 / Companhia Nacional de Abastecimento. Brasília, Conab. Disponível em: http://www.conab.gov.br/OlalaCMS/ uploads/arquivos/11_12_08_10_58_12_08.pdf. Acessado em: 03 de janeiro de 2012 .

Costa MM, Mauro AO, Unêda-Trevisoli SH, Arriel NHC, Bárbaro I M \& Muniz FRS (2004) Ganho genético por diferentes critérios de seleção em populações segregantes de soja Pesquisa Agropecuária Brasileira, 39:1095-1102.

Cruz CD (2008) Programa Genes - Diversidade genética. $1^{\text {a }}$ ed. Viçosa, Editora UFV. 278p.

Cruz CD, Regazzi AJ \& Carneiro PCS (2004) Modelos biométricos aplicados ao melhoramento genético. $3^{\text {a }}$ ed. Viçosa, Editora UFV. 480p.

Embrapa - Empresa Brasileira de Pesquisa Agropecuária (2006) Centro Nacional de Pesquisa de Solos. Sistema Brasileiro de Classificação de Solos. Rio de Janeiro. 412p.

Iqbal M, Chang MA \& Iqbal MZ (2003) Correlation and path coefficient analysis of earliness and agronomic characters of upland cotton in Multan. Pakistan Journal of Agronomy, 2:160168.

Iqbal Z, Arshad M, Ashraf M, Mahmood T \& Waheed A (2008) Evaluation of Soybean [Glycine max (1.) Merrill] germplasm for some important morphological traits using multivariate analysis. Pakistan Journal of Botany, 40:2323-2328.

Lopes AC de A, Vello NA, Pandini F, Rocha M de M \& Tsutsumi CY (2002) Variabilidade e correlações entre caracteres em cruzamentos de soja. Scientia Agrícola, 59:341-348.

Malik MFA, Ashraf M, Qureshi AS \& Ghafoor A (2007) Assessment of genetic variability, correlation and path analyses for yield and its components in soybean. Pakistan Journal of Botany, 39:405-413.

Malik MFA, Ashraf M, Qureshi AS \& Khan MR (2011) Investigation and comparison of some morphological traits of the Soybean populations using cluster analysis. Pakistan Journal of Botany, 43:1249-1255.

Miranda GV (1998) Diversidade genética e desempenho de cultivares de soja como progenitores. Tese de Doutorado. Universidade Federal de Viçosa, Viçosa. 117p.

Peluzio JM, Vaz-de-Melo A, Afférri FS, Silva RR, Barros HB, Nascimento IR \& Fidelis RR (2009) Variabilidade genética entre cultivares de soja, sob diferentes condições edafoclimáticas. Pesquisa Aplicada \& Agrotecnologia, 2:21-29.

Rinaldi DA, Pípolo VC, Gerage AC, Ruas C de F, Fonseca N da S, Souza A de, Souza SGH de \& Garbuglio DD (2007) Correlação entre heterose e divergência genética estimadas por cruzamentos dialélicos e marcadores RAPD em populações de milhopipoca. Bragantia, 66:183-192.

Santos ER, Barros HB, Ferraz E de C, Capone A, Santos AF dos \& Fidelis RR (2011) Divergência entre genótipos de soja, cultivados em várzea irrigada. Revista Ceres, 58:755-764. 
SBCS - Sociedade Brasileira de Ciência do Solo (2004) Núcleo Regional Sul/Comissão de Química e Fertilidade do Solo. Manual de adubação e calagem para os estados do RS e SC. Porto Alegre. 400p.

Scott AJ \& Knott MA (1974) Cluster analysis methods for grouping, means in the analysis of variance. Biometrics, 30:507512.

Sediyama T, Teixeira RC \& Reis MS (2005) Melhoramento da soja. In: Borém A (Ed.) Melhoramento de espécies cultivadas. Viçosa, Editora UFV. p.897-930.
Sihag R, Hooda JS, Vashishtha RD \& Malik BPS (2004) Genetic divergence in soybean [Glycine max (L.) Merrill]. Annual Biological, 20:17-21.

Singh D (1981) The relative importance of characters affecting genetic divergence. The Indian Journal of Genetics \& Plant Breeding, 41:237-245.

Vieira C (2007) Cultura do feijão. $2^{a}$ ed. Vicosa, UFV. 146p.

Vieira ESN, Schuster I, Silva SB \& Oliveira MAR (2009) Variabilidade genética em cultivares de soja determinada com marcadores microssatélites em gel de agarose. Pesquisa Agropecuária Brasileira, 44:1460-1466. 